\title{
Visible Light-Controlled Living Cationic Polymerization of Methoxystyrene
}

\author{
Lei Wang, Yupo Xu, Quan Zuo, Haojie Dai, Lei Huang, Meng Zhang, Yongli Zheng, \\ Chunyang Yu, Shaodong Zhang*, and Yongfeng Zhou*
}

\begin{abstract}
Photo-controlled living polymerization has received great attention in recent years. However, despite the great success therein, the report on photo-controlled living cationic polymerization has been greatly limited. We demonstrate here a novel decolorable, metal-free and visible light-controlled living cationic polymerization system by using tris(2,4-dimethoxyphenyl)methylium tetrafluoroborate as the photocatalyst and phosphate as the chain transfer agent (CTA) for polymerization of 4-methoxystyrene. This polymerization reaction under green LED light irradiation shows clear living characteristics including predictable molar mass, narrow molar-mass dispersity $(\Theta=1.25)$, and sequential polymerization capability. In addition, the photocatalytic system exits excellent "on-off" photo switchability and shows the longest "off period" of $36 \mathrm{~h}$ up to now for photo-controlled cationic polymerization. Furthermore, the residual photo-catalyst is easily deactivated and decolored with addition of a base after the polymerization.
\end{abstract}

\section{Introduction}

In the last decade, considerable attention has been paid to living polymerizations mediated by external stimuli (mechanical, electro-chemical, etc. ${ }^{1}$ Among these stimuli, the use of light source is very attractive because of its great capacity on spatio-temporal control of the polymerization process, apart from the control of polymer chain length, narrow dispersity endowed by their living feature. For example, pioneered by Hawker and coworkers, ${ }^{2}$ photo-induced atom transfer radical polymerization (photo-ATRP) has been quickly developed in the last few years, which employs a variety of photocatalysts including $\operatorname{Ir}(\mathrm{ppy})_{3},{ }^{2 \mathrm{a}}$ perylene, ${ }^{2 \mathrm{c}}{ }^{10-}$ methylphenothiazine, ${ }^{2 \mathrm{~d}} \mathrm{~N}$-aryl phenothiazine, ${ }^{2 \mathrm{e}} \mathrm{N}, \mathrm{N}$-diaryl dihydrophenazine,${ }^{2 \mathrm{f}} \mathrm{N}$-aryl phenoxazine,${ }^{2 \mathrm{~g}}$ dimethyl dihydroacridines, ${ }^{2 h}$ oxygen-doped anthanthrene, ${ }^{2 \mathrm{i}}$ and other organic photocatalysts (OPCs) with complex

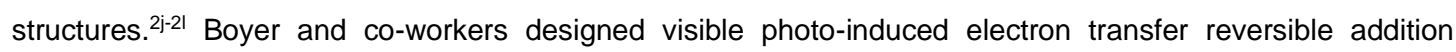
fragmentation chain transfer (PET-RAFT) polymerizations with various photocatalysts and thiocarbonylthio compounds as chain transfer agent (CTA), which showed excellent on-off switching of the living polymerization. ${ }^{3}$ Ring-opening metathesis polymerization (ROMP) ${ }^{4}$ and ring-opening polymerization $(\mathrm{ROP})^{5}$ triggered by visible light regulation have also been reported.

Up to date, the photo-regulated polymerization strategy of vinyl monomers has mainly focused on the living radical polymerization (LRP), while its application to living cationic polymerizations had surprisingly been overlooked with only few exceptions. ${ }^{6}$ Among them, Fors and coworkers pioneered it by using 2,4,6-tris(pmethoxyphenyl) pyrylium tetrafluoroborate (Figure 1) as the photoredox catalyst to synthesize poly(vinyl ether)s with controlled molar mass and narrow dispersity under irradiation of blue light-emitting diodes. ${ }^{6 b}$ Aiming at improving the temporal control of this method, the same group employed more stable Iridium complexes, which permitted excellent on-off switching of the chain growth (Figure 1). ${ }^{6 c}$ Liao and coworkers later realized photocontrolled living cationic polymerization of vinyl ethers by employing bisphosphonium salts as photocatalysts (Figure 1). ${ }^{6 \mathrm{~d}}$ These rare exmaples show the field of photo-controlled living cationic polymerizations is at its infancy, and the broadening of the scope of new photoredox catalysts and monomers is highly demanding. ${ }^{7}$ 


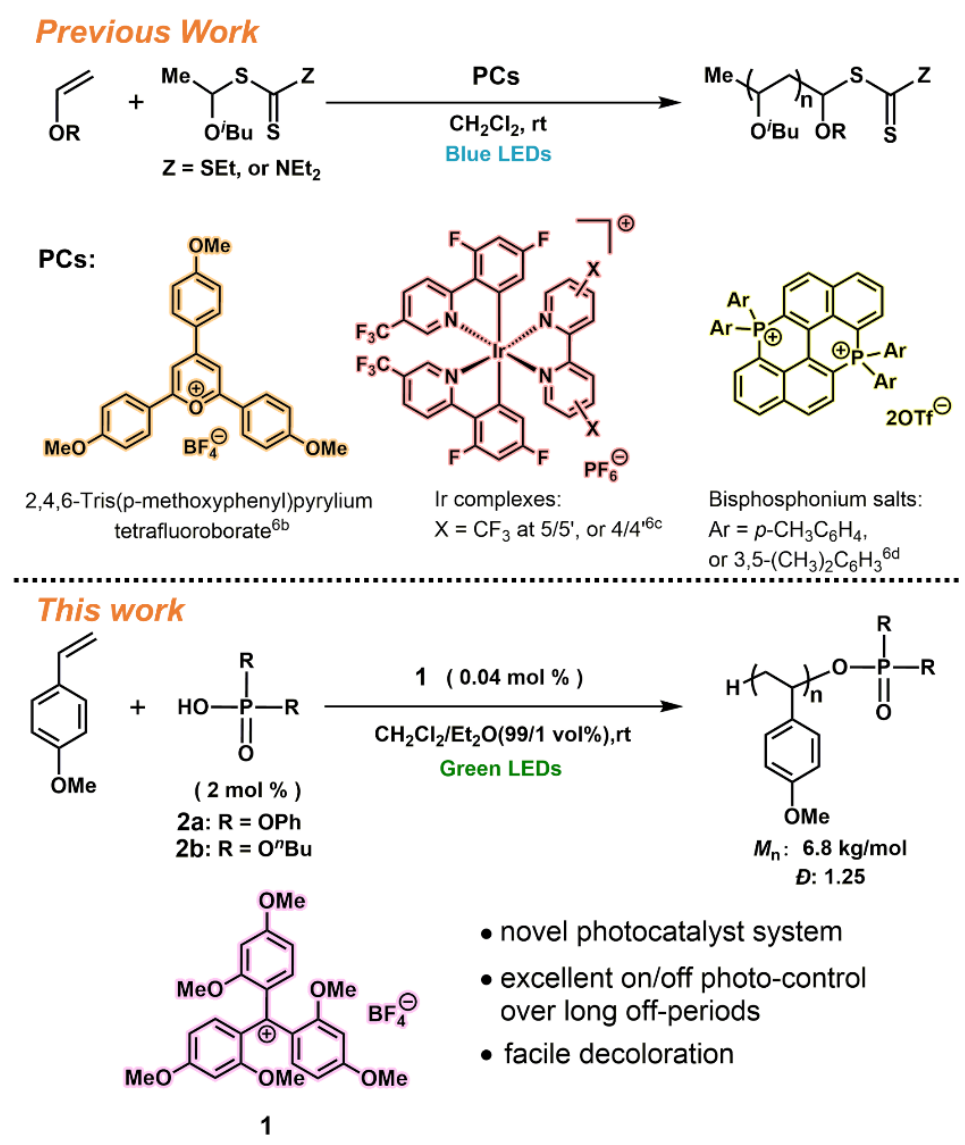

Figure 1. Recent reported in visible light driven photo-controlled living cationic polymerization.

Furthermore, the reported photo-induced living polymerization systems generally suffer from the problems brought by residual photocatalysts. These residual photocatalysts trapped in the polymer matrix can cause color contamination $^{2 i}$ or heavy metal toxicity if the catalysts are metal ion-loaded, which greatly limit the potential applications of these polymers in fields including advanced photoelectronic materials and biomaterials. ${ }^{8}$ In addition, they will induce polymer degradation and side reactions due to strong oxidization of excited state photocatalysts under light. Although several methods such as column chromatography, precipitation, and centrifugation have been tried to eliminate the catalytic residual, ${ }^{9}$ these procedures are often nontrivial and costly. Therefore, endeavor is also urgently required to readily remove or decrease residual photocatalysts.

In this article, we therefore report on a new photocatalytic system composed of OPC tris(2,4dimethoxyphenyl)methylium tetra-fluoroborate (1) and phosphate CTAs, so to realize visible light-mediated living cationic polymerization by using 4-methoxystyrene ( $p$-MOS) as a proof-of-concept monomer. This reaction shows clear living characteristics including predictable molar mass, narrow molar-mass dispersity, and sequential polymerization capability. In addition, this polymerization system shows excellent photo "on-off" switching ability: the polymerization only occurs in a living way under light irradiation, while totally halts in the dark period up to $36 \mathrm{~h}$, which is, to our knowledge, the record of dormant period up to now for photo-controlled cationic polymerization. Moreover, the erstwhile dark purple photocatalyst can be decolored and deactivated by simply reacting with an alkaline after the polymerization. Such a photocatalyst deactivation method circumvents the tedious decoloration and catalyst removal process in conventional photo-induced polymerizations.

\section{Results and Discussion}


The Photophysical and Electronic Properties of OPC 1. It has been previously demonstrated that triarylmethyl cations can undergo reversible redox processes via single electron transfer (SET). ${ }^{10}$ Among them, triphenylmethyl cation was extensively studied as very efficient activators and as one-electron oxidants for olefin polymerization reactions. ${ }^{11}$ However, it hitherto has not been applied to visible photoinduced reaction, let alone living polymerizations. In the current study we demonstrate, for the first time, that it can serve as a powerful photocatalyst to achieve visible light-induced living cationic polymerization of $p$-MOS.

OPC 1 was prepared by one-pot synthesis as a dark purple solid in $83 \%$ yield (see synthetic details in Supporting Informaiton), which exhibits good solubility in common solvents like dichloromethane $\left(\mathrm{CH}_{2} \mathrm{Cl}_{2}\right)$. Its UV/vis absorption spectrum shows a characteristic twin absorption band at $\lambda_{\max }=517\left(\varepsilon_{\max }=49500 \mathrm{M}^{-1} \mathrm{~cm}^{-1}\right)$ and $553 \mathrm{~nm}\left(\varepsilon_{\max }=51000 \mathrm{M}^{-1} \mathrm{~cm}^{-1}\right)$ in $\mathrm{CH}_{2} \mathrm{Cl}_{2}$, therefore allowing for the absorption of low-energy green light source (Figure 2a). OPC 1 exhibits an excellent photochemical stability, as no change in absorption was observed after 12 hours of $5 \mathrm{~W}$ green LED light irradiation (Figure S5). Its cyclic voltammogram shows a highly reversible redox wave under argon atmosphere, which corresponds to the transition from 1 to 1 • radical (Figure $2 b)$. It has a relatively lower ground state potential $\left(E_{1 / 2}=-0.36 \mathrm{~V}\right.$ vs. SCE) as compared to other reported methoxy-substituted triarylmethyl cations (Table S1), and its excited state potential is at $+1.55 \mathrm{~V}$ vs. SCE according to Equation $1 .^{12}$

$$
E_{O x}\left[P C^{*+} / P C^{\bullet}\right]=E_{R e d}\left[P C^{+} / P C^{\bullet}\right]+\Delta E_{\text {excit }}\left[P C^{+} / P C^{*+}\right]
$$

The excitation energy, $\Delta E_{\text {excit }}\left[P C^{+} / P C^{*+}\right]$ can be obtained from the fluorescence spectra (Figure 2c). The lower potential is not only beneficial to the stability of the catalyst and monomer mixture in a dark environment, but also to the recapturing of propagating cationic species and deactivation of polymerization (vide infra). These photophysical properties of $\mathbf{1}$ therefore prompted us to attempt its application to photo-controlled living polymerization.

The Photoinduced Electron Transfer between OPC 1 and Phosphate CTAs. Beside photocatalyst 1, a suitable CTA is also necessary for photoinduced cationic living polymerization. The efficient CTAs for such purpose are so far limited to sulfur compounds. ${ }^{6,13}$ Although these CTAs are widely used for chain transfer related CRP, their unpleasant odor and residual color hurdle their large-scale applications. ${ }^{14}$ In contrast, phosphate derivatives are a type of biochemical intermediates that are readily accessible, non-toxic, colorless and odorless. The Kamigaito group used phosphates as CTAs for cationic RAFT polymerization of vinyl ethers. ${ }^{15}$ However, to our knowledge, they haven't been used for photo-controlled living polymerization.

In the current study, diphenyl phosphate (2a) or dibutyl phosphate (2b) with predetermined quantities were first mixed with photocatalyst 1 , so as to ascertain its stability in the presence of nucleophilic $P(O) O-R$ groups before irradiation. ${ }^{16}$ The characteristic absorption of $\mathbf{1}$ was unambiguously observed without any change of absorption in visible region, suggesting no reaction occurred between $\mathbf{1}$ and phosphate CTA at the ground state (Figure S6, Figure S7). 
a)

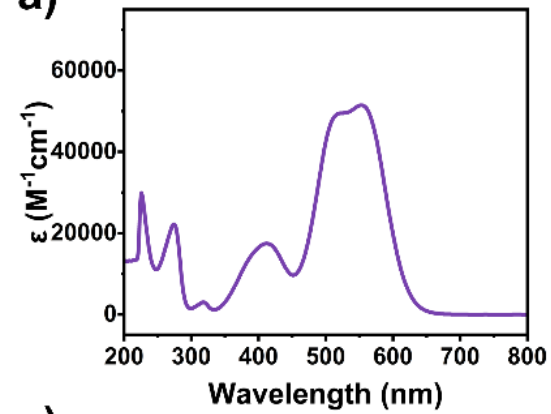

c)

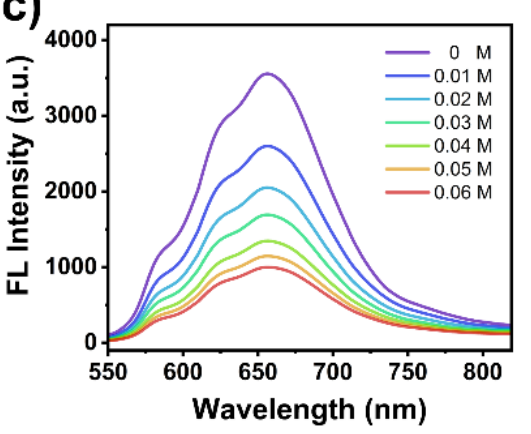

b)

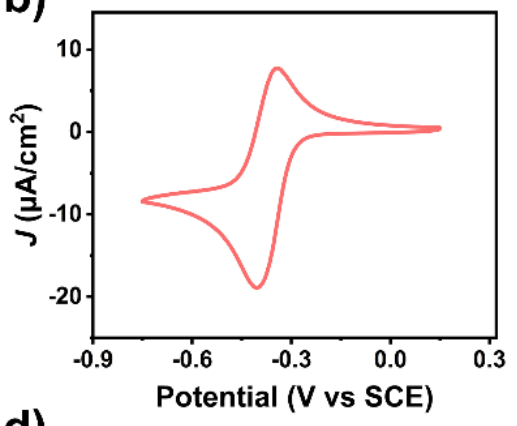

d)

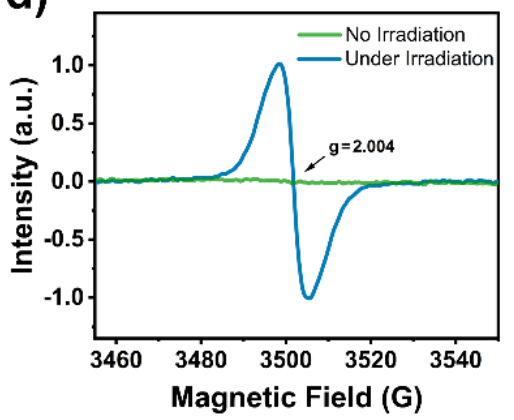

Figure 2. a) UV absorption spectrum of 1. b) The cyclic voltammogram of 1. c) Fluorescence changes of photocatalyst 1 with the addition of 2a. d) Steady-state electron spin resonance spectrum of 1 with 2 a under $532 \mathrm{~nm}$ irradiation.

Table 1. Visible Light-Mediated Living Cationic Polymerization of $p-M^{a}$

\begin{tabular}{cccccccc}
\hline Entry & CTA & 1 : CTA : & Time & Conv. $\%$ & $M_{\mathrm{n}}(\exp )^{\mathrm{b}}(\mathrm{kg} / \mathrm{mol})$ & $M_{\mathrm{n}}(\mathrm{theo})^{\mathrm{c}}(\mathrm{kg} / \mathrm{mol})$ & $D^{\mathrm{b}}$ \\
\hline 1 & $\mathbf{2 a}$ & $0: 2: 100$ & 60 & 0 & - & - & - \\
2 & - & $0.04: 0: 100$ & 60 & 99 & 103.7 & - & 1.65 \\
3 & $\mathbf{2 a}$ & $0.08: 2: 100$ & 40 & 98 & 6.9 & 7.2 & 1.29 \\
4 & $\mathbf{2 a}$ & $0.04: 2: 50$ & 60 & 91 & 3.7 & 3.4 & 1.27 \\
5 & $\mathbf{2 a}$ & $0.04: 2: 100$ & 60 & 87 & 7.1 & 6.4 & 1.25 \\
6 & $\mathbf{2 a}$ & $0.08: 2: 200$ & 60 & 83 & 15.2 & 12.0 & 1.27 \\
7 & $\mathbf{2 b}$ & $0.08: 2: 100$ & 200 & 95 & 7.0 & 6.9 & 1.26 \\
8 & $\mathbf{2 b}$ & $0.04: 2: 50$ & 200 & 91 & 3.8 & 3.4 & 1.25 \\
9 & $\mathbf{2 b}$ & $0.04: 2: 100$ & 200 & 89 & 7.2 & 6.5 & 1.23 \\
\hline
\end{tabular}

aPolymerization conditions: $p$-MOS (1 equiv.), $\mathbf{1}(0.04-0.08 \mathrm{~mol} \%)$, and $\mathbf{2 a}$ or $\mathbf{2 b}(1.0-4.0 \mathrm{~mol} \%)$ at room temperature in $\mathrm{CH}_{2} \mathrm{Cl}_{2} / \mathrm{Et}_{2} \mathrm{O}$ $\left(99 / 1\right.$ vol\%) under green LED irradiation. b Determined by GPC, relative to polystyrene standards. ${ }^{c} M_{n}$ (theo) is the theoretical numberaverage molar mass calculated on the basis of the equation $M_{n}$ (theo) $=[\mathrm{M}]_{0} /[\mathrm{CTA}]_{0} \times \mathrm{MW}^{\mathrm{M}} \times \mathrm{conv}_{\mathrm{O}} \%+\mathrm{MW} \mathrm{WAT}^{\mathrm{CA}}$, where $[\mathrm{M}]_{0},[\mathrm{CAT}]_{0}$, $\mathrm{MW}^{\mathrm{M}}$, and MW $\mathrm{MAT}^{\mathrm{CAT}}$ correspond to initial monomer concentration, initial CTA concentration, molecular weight of monomer, and molecular weight of CTA agent, respectively.

The photoinduced electron transfer (PET) process between 1 and phosphate CTA was then monitored by steady-state fluorescence spectroscopy. ${ }^{17}$ The fluorescence of 1 in $\mathrm{CH}_{2} \mathrm{Cl}_{2}$ was gradually quenched by addition of $\mathbf{2} \mathbf{a}$ or $\mathbf{2} \mathbf{b}$ without formation of new emission band (Figure 2 c, Figure S8), indicating an effective PET process between $\mathbf{1}$ and $\mathbf{2 a}$ or $\mathbf{2 b}$. The rate constants of the fluorescence quenching of $k_{\mathrm{q}}$, was determined by Stern-Volmer equation (Equation 2).

$$
F_{0} / F=1+k_{q} \tau_{3}[Q]
$$

Where $F_{0}$ is the fluorescence intensity before addition of quencher, $t$ is the fluorescence lifetime of the catalyst, and $[Q]$ is the concentration of quencher. The $k_{\mathrm{q}}$ was determined to be $1.49 \times 10^{10} \mathrm{M}^{-1} \mathrm{~S}^{-1}$ for $2 \mathrm{a}$ and $1.17 \times 10^{8} \mathrm{M}^{-}$ ${ }^{1} \mathrm{~S}^{-1}$ for $\mathbf{2 b}$, respectively. These results therefore revealed considerably efficient PET process between photocatalyst $\mathbf{1}$ and the two CTA molecules, among which phosphate $\mathbf{2 a}$ is more potent. Besides, the 
bimolecular quenching constant $k_{\mathrm{q}}$ of $2 \mathrm{a}$ at ca. $10^{10} \mathrm{M}^{-1} \mathrm{~S}^{-1}$ suggest that this PET proceeds via a diffusioncontrolled process. ${ }^{13 b}$

The fluorescence decay of 1 was also measured using $532 \mathrm{~nm}$ pulsed excitation, and its lifetime continuously decreased with in-creasing amount of $\mathbf{2 a}$, which also confirms the aforementioned PET process (Figure S10). Meanwhile, the electron spin resonance (ESR) spectroscopy was measured to further verify PET process between $\mathbf{1}$ and $\mathbf{2 a}$ (Figure 2d). When $\mathbf{1}$ was directly irradiated by green LED, no free radical signal was observed. In contrast, when mixed with 2a, photocatalyst 1 under irradiation with $532 \mathrm{~nm}$ light generated an ESR signal with $\mathrm{g}=\mathbf{2 . 0 0 4}$, corresponding to a free radical species that can be assigned to $\mathbf{1} \bullet$ (Figure 2d).

With the above-mentioned clues, we postulated that phosphate CTA $\mathbf{2} \mathbf{a}$ or $\mathbf{2} \mathbf{b}$ can be oxidized into a radical cation by photo-excited 1 via PET process, and their combination might provide a novel catalytic system for photo-mediated living cationic polymerization.

Living Polymerization of $p$-MOS Triggered by Visible Light. As a proof of concept, the application of the novel photocatalytic system of CTA $\mathbf{2 a}$ or $\mathbf{2} \mathbf{b}$ and OPC $\mathbf{1}$ to visible light-induced living polymerization was tested with $p$-MOS as proof-of-concept mon-omer. The polymerization reaction was conducted at room temperature in a solvent mixture of $\mathrm{CH}_{2} \mathrm{Cl}_{2}$ and $\mathrm{Et}_{2} \mathrm{O}(99 / 1$ vol\%) under argon atmosphere, which was triggered with a light source of $5 \mathrm{~W}, 532 \mathrm{~nm}$ LED (Figure 1).

As can be seen from Table 1 (entry 1 ), no reaction occurred in the absence of OPC $\mathbf{1}$. Without $\mathbf{2 a}$ or $\mathbf{2 b}$ but only photocatalyst 1 (entry 2), the polymerization yielded the polymers with $\oslash=1.65$. It indicates OPC 1 can directly activate the monomer, leading to an uncontrolled polymerization, ${ }^{13 b}$ which is in agreement with their oxidative potentials that will be discussed in detail in the mechanistic section (vide infra). On the other hand, when CTA $\mathbf{2 a}$ or $\mathbf{2 b}$ and photocatalyst $\mathbf{1}$ were both present the polymerizations progressed steadily (entries $\mathbf{3}$ 9), as will also be discussed afterwards.

The resulting polymers were characterized by ${ }^{1} \mathrm{H}$ NMR spectroscopy. Taking the polymers from entry 4 for example (Figure 3), observed were the prominent peaks assigned to the repeating units of poly( $p$-MOS) mainchain at $1.25-2.50 \mathrm{ppm}(a, b), 3.79 \mathrm{ppm}(d)$, and $6.60 \mathrm{ppm}(c)$, respectively. In addition, the peaks of the chain ends were also found, with the small peaks at 7.20-7.42 ppm $(g), 5.39 \mathrm{ppm}(f)$ and $1.02 \mathrm{ppm}(e)$ corresponding to the phenyl groups, the acetal-methine protons at the $\omega$-chain end linked to the phosphate ester $\mathbf{2 a}$, and $-\mathrm{CH}_{3}$ in the $\alpha$-chain end of the polymers, respectively. The number-average molar mass $M_{n}$ of the polymers measured by gel permeation chromatography (GPC) is $6.9 \mathrm{~kg} / \mathrm{mol}$, which complies with the degree of polymerization $\left(D P_{\mathrm{n}}\right.$ $=\mathrm{H}_{\mathrm{d}} / \mathrm{H}_{3 \mathrm{f}}, M_{\mathrm{n}, \mathrm{NMR}}=7.1 \mathrm{~kg} / \mathrm{mol}$ ) calculated from the ${ }^{1} \mathrm{H}$ NMR analysis.

The chemical nature of the resulting polymers was also examed by matrix-assisted laser desorption/ionization time-of-flight mass spectroscopy (MALDI-TOF MS). Due to the relatively weak $\mathrm{P}(\mathrm{O}) \mathrm{O}-\mathrm{R}$ bonds of phosphate, the resulting poly( $p$-MOS) using $\mathbf{2 a}$ as CTA bears dibutyl phosphate end group that is rather labile to undergo hydrolysis during the sample preparation process (Figure S13), a MALDI-TOF-MS spectroscopy analysis of poly( $p$-MOS) using $\mathbf{2} \mathbf{b}$ was therefore performed to further investigate the chain-end structure. It clearly confirms the silver cationized polymer chains bearing a methyl at one chain end, and the other end group is a double bond (Figure $3 b$ ), which is commonly observed for poly( $p$-MOS) produced by cationic polymerization after strong laser bombarding during MALDI procedure. ${ }^{18}$ 

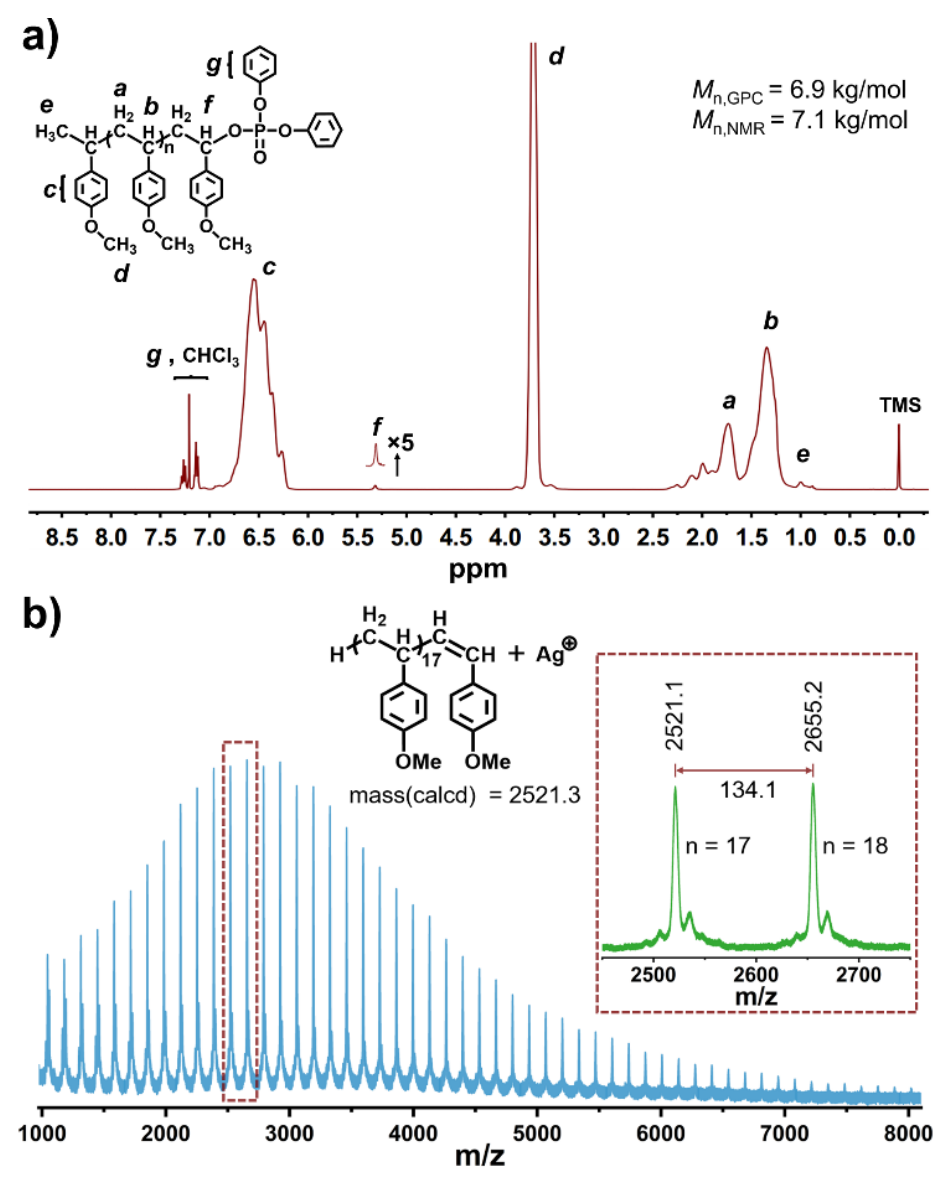

Figure 3. a) ${ }^{1} \mathrm{H}$ NMR and b) MALDI-TOF spectra of the resulting poly(p-MOS) with red box in the top right showing two peaks of 2521.1 and 2655.2 corresponding to poly $(p-M O S)\left(D P_{n}=18\right.$ and 19$)$ cationized by silver and bearing a terminal group of double bond.

We also carried out the kinetic study of the photo-induced polymerization, which was monitored by ${ }^{1} \mathrm{H}$ NMR and GPC. For both CTA $2 \mathbf{a}$ and $\mathbf{2 b}$, the $\ln \left([\mathrm{M}]_{0} /[\mathrm{M}]_{\mathrm{t}}\right.$ ) as a function of time (Figure $4 \mathrm{a}$ and $4 \mathrm{c}$ ) and plots of $M_{\mathrm{n}}$ against conversion (Figure $4 \mathrm{~b}$ and $4 \mathrm{~d}$ ) unambiguously reveal the first-order kinetic behavior, which therefore confirms the high degree of polymerization control. Besides, as expected for a living polymerization system, the molar mass dispersity $(\Theta)$ gradually decreased from 1.41 to 1.25 with the increase of monomer conversion (Figure $4 \mathrm{~b}$ and $4 \mathrm{~d}$ ). It is also noteworthy that $\mathbf{2 a}$ accelerated the polymerization more than its dibutyl counterpart $\mathbf{2 b}$ did, as the polymerization with 2a was completed within 60 min (entries 3-6), while at least 200 min was needed (entries 7-9, Table 1). This tendency is in line with the greater bimolecular quenching constant $k_{\mathrm{q}}$ of $2 \mathrm{a}$ during its PET process with OPC 1 (vide supra).

We further performed the sequential monomer addition experi-ment so as to verify the chain-end fidelity (Figure $4 \mathrm{e}$ ). After the full consumption of $p$-MOS that yielded the polymers with $M_{\mathrm{n}}=5.3 \mathrm{~kg} / \mathrm{mol}$ and $\oplus=1.23$, the irradiation was switched off. When an-other equivalent portion of monomer was added to the solution, the propagation resumed upon the turn-on of irradiation. This second step yielded the extended polymer with a $M_{\mathrm{n}}$ $=10.7 \mathrm{~kg} / \mathrm{mol}$, along with a monomodal distribution and low value of $\Theta=1.25$ ). The $M_{\mathrm{n}}$ increment of $5.4 \mathrm{~kg} / \mathrm{mol}$ in the prolonged polymer chain agrees well with the theoretical value. 

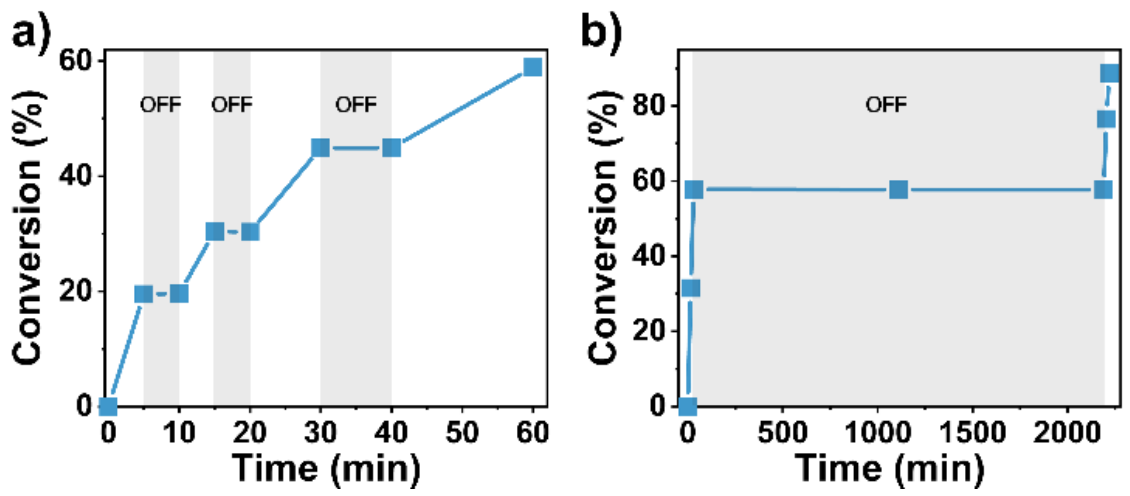

Figure 5. Temporal control of polymer chain growth via on-off light switching. a) Monomer conversion of $p$-MOS by using OPC 1 and CTA 2a with short dark intervals. b) Prolonged dark period (36 h) to demonstrate excellent temporal control.

Taking together the first-order kinetic, predeterminable molar mass, narrow molar-mass distribution and chainend fidelity, we therefore confirmed our photo-induced polymerization unambigu-ously exhibits a living feature. We then set out to search for the optimal reaction conditions (Table 1). We also found, increasing the catalyst loading raised the polymerization rate (entry 3 vs. entry 5). After optimizing the reaction conditions, we chose the parameters listed in entry 4 , Table 1 for the following study.

Excellent On-Off Photo-Switching Characteristics. A unique feature of light-mediated polymerizations is their excellent temporal control over chain propagation by on-off switching of light source. We first attempted to stir the reaction mixture of $p$-MOS, $2 a$, and $\mathbf{1}$ under the optimized conditions in dark for $12 \mathrm{~h}$, and no polymerization was noticed. The intermittent on-off irradiations were then applied to the mixture, and ${ }^{1} \mathrm{H}$ NMR was used to monitor at each switching point for the determination of conversion rate. The polymerization proceeded only under light irradiation, which immediately ceased upon removal of light stimulus (Figure 5a). It is worth mentioning, after iteration of several on-off switchings, that the final polymer exhibited a unimodal molar mass distribution with a low $\Theta$ value of 1.28 , comparable to that of the as-synthesized polymers without intermittent exposure (Figure S15).

To better evaluate the photo-controlled characteristics of the living polymerization process, the intermittent irradiation experiments with a long interval in dark period of 24 or $36 \mathrm{~h}$ were respectively conducted, right after an initial photo-polymerization to a high rate of conversion was achieved (Figure 5). It was found that almost no change in monomer conversion occurred in these dark periods, as the reaction was totally halted; the reaction was woken again after the green light was turned on. This dormant period reached up to $36 \mathrm{~h}$, which is, to the best of our knowledge, the longest reported so far for the photo-controlled cationic polymerization, indicating the considerable stability of OPC 1, which therefore exerts excellent temporal control of the polymer propagation.

The Mechanistic Study of Photo-Mediated Living Cationic Polymerization. Since CTA $\mathbf{2 a}$ or $\mathbf{2 b}$ probably can be converted into cationic radical with OPC $1,{ }^{17}$ the reaction reported herein can proceed either via radical or cationic polymerization. We first attempted in vain the polymerization of methyl acrylate (MA), which therefore presumably precludes the possibility of radical polymerization. Meanwhile, we found that the polymerization of $p$-MOS under the optimal conditions was quenched upon addition of the cationic scavenger $\mathrm{MeOH}(10 \mathrm{vol} \%)$, which therefore suggests the polymerization might comply with a cationic mechanism. 
To get a further insight into the mechanism of photo-mediated living polymerization brought by phosphate CTA, the potentials corresponding to the onset of oxidation of CTA $\mathbf{2} \mathbf{a}, \mathbf{2} \mathbf{b}$, and $p$-MOS were determined in acetonitrile by cyclic voltammetry (Figure S17). It showed that the excited potential of $1\left(E^{\star}=+1.55 \mathrm{~V}\right.$ vs. SCE) was sufficient to oxidize both CTAs $\left(E^{0}{ }_{2 a / 2 a \cdot+}=+0.72 \mathrm{~V}\right.$ vs. SCE for $2 \mathbf{a}$, and $E^{0}{ }_{2 b / 2 b \cdot+}=+0.69 \mathrm{~V}$ vs. SCE for $\mathbf{2 b}$ ) and $p$-MOS $\left(E^{0}=+1.09 \mathrm{~V}\right.$ vs. SCE). As mentioned above, although the monomer can be oxidized by the photoexcited OPC 1, the polymerization proceeded in an uncontrolled manner. On the other hand, excellent control was achieved in the presence of CTA. Together with these polymerization experiments in comparison, the different potentials reveal that, as compared with $p$-MOS, $\mathbf{2 a}$ and $\mathbf{2} \mathbf{b}$ are more readily to be oxidized by photocatalyst 1. It therefore implies that once the oxidized monomers are formed, if there is any, may undergo a second electron transfer to the CTA molecules, which prevents the uncontrolled polymerization by direct oxidation of monomers with OPC 1 (Entry 2, Table 1). ${ }^{13 \mathrm{~b}}$

We also conducted the electro-polymerization of $p$-MOS with CTA $\mathbf{2 b}$ for reference. The potential of the mixture of $\mathbf{2} \mathbf{b}$ and $p$-MOS was determined to be $+0.70 \mathrm{~V}$ vs. SCE (Figure S18), which is $0.39 \mathrm{~V}$ lower than that of pure $p$-MOS. Above the potential of $+0.95 \mathrm{~V}$, this mixture was found to yield the polymers with broad dispersity $(\theta=$ 1.65), whereas no polymerization was noticed in the absence of $\mathbf{2} \mathbf{b}$ under the same conditions. This result confirms the hypothesis that the major pathway for this light-mediated polymerization proceeds via direct oxidation of phosphate CTA.

a) Photo-Induced Initiation, Propagation and Formation of Adduct

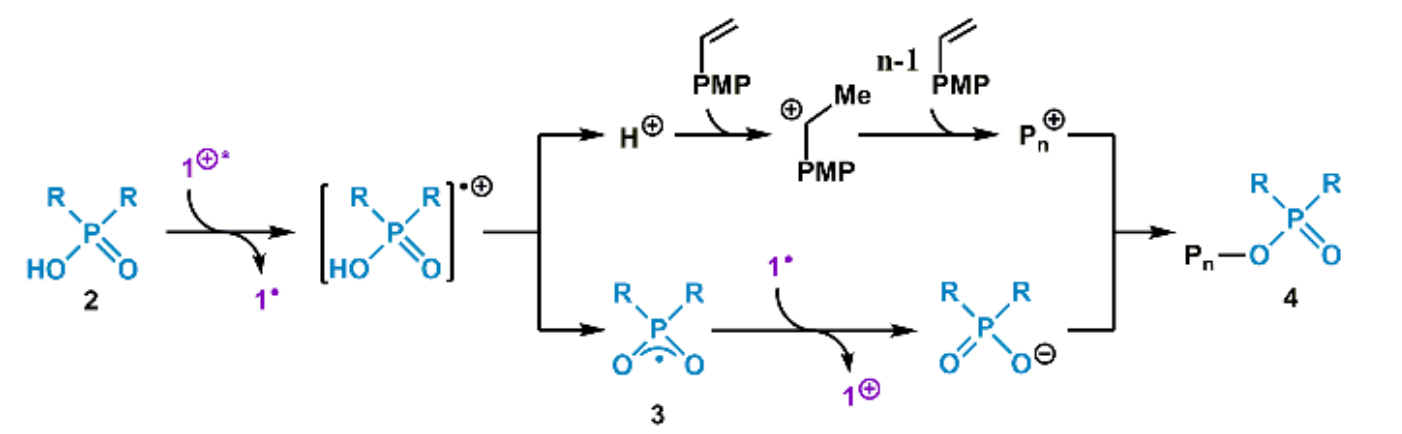

b) Visible Light-Mediated Activation and Deactivation

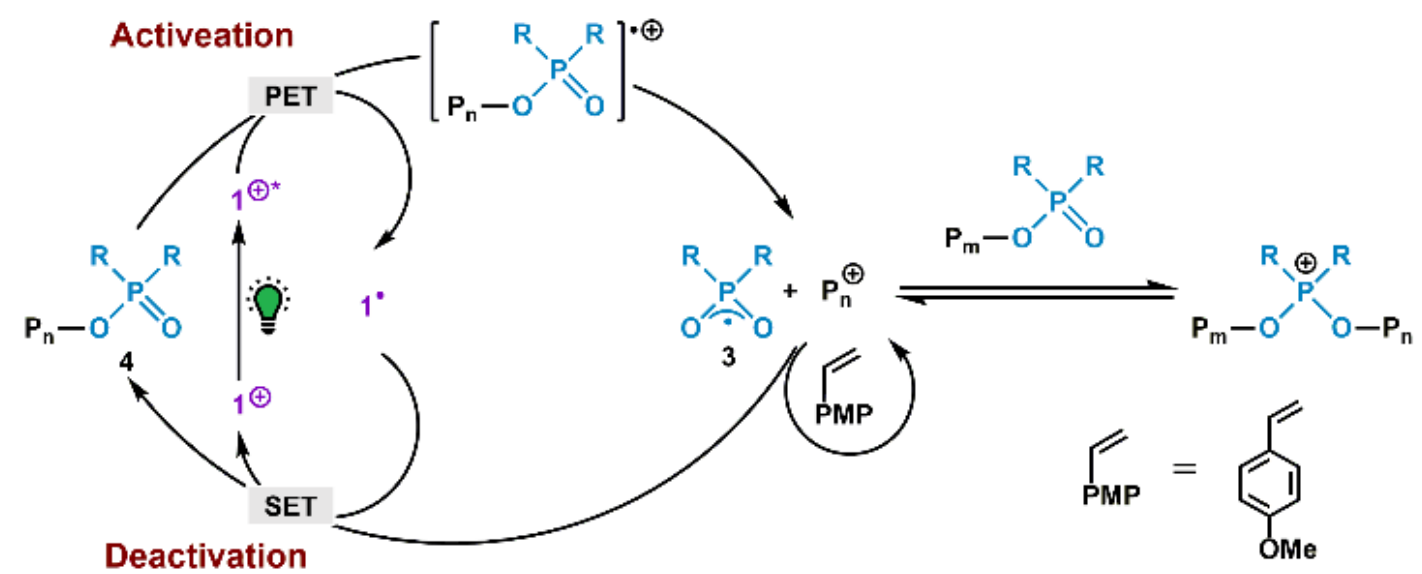

Figure 6. Proposed mechanism for the photo-mediated living cationic polymerization of $p$-MOS with OPC 1 and phosphate CTA. 
Putting all the evidences together, we therefore propose that the photo-controlled living cationic polymerization proceeds as follows (Figure 6). Upon photo irradiation under green LED, the cation of OPC 1 is excited, which oxidizes the phosphate CTA 2 via PET process, leading to the formation of the corresponding radical cation (Figure 6). The subsequent mesolytic cleavage of this radical cation generates two species: firstly, it releases a proton to initiate $p$-MOS monomer and creates an active cationic species, which then induces the chain propagation, presented as $\mathrm{P}_{\mathrm{n}}{ }^{\oplus}$; secondly, it also generates species $\mathbf{3}$, which is reduced by stable radical $\mathbf{1} \bullet$ to yield the corresponding phosphate anion. The resulting $P_{n} \oplus$ and phosphate anions could combine into an adduct 4 as the dormant species.

Subsequently, the phosphate of $\mathbf{4}$ can be constantly oxidized by the excited OPC 1 and keeps releasing the active cation for polymer chain growth (Figure 6). ${ }^{19}$ With the presence of phosphate 4 , the chain propagation is controlled via a phosphonium intermediate that participates in a RAFT-like degenerative chain transfer process. Ultimately, the cationic species $\mathrm{P}_{\mathrm{n}}{ }^{\oplus}$ and radicals $\mathbf{3}$ can be deactivated by the SET process from $\mathbf{1} \bullet$ to regenerate the dormant species 4 . The activation and deactivation process happen continuously, leading to the iterative polymer chain growth thorough a living cationic polymerization process. However, when the light turns off, the catalytic cycle will be closed at the species 4 , which can be reactivated when the light turns on.

Decoloration of Visible Light-Mediated Polymerization. As stated in the Introduction, it is nontrivial and costly to remove re-sidual photocatalysts of photoinduced polymerization, which im-pose color contamination ${ }^{2 i}$ and polymer degradation ${ }^{8}$ of the resulting polymers. By virtue of the Lewis acid-nature of our OPC 1 , we reasoned that it could be simultaneously decolored and deactivated by simple addition of a base after the reaction. We therefore set out to verify our assumption by adding 2-fold molar excess of triethylamine relative to OPC 1 into the reaction mixture. To our delight, the erstwhile purple color of the solution started fading until this total disappearance within five minutes (Figure 7a, inset), and this color change was also witnessed by UV/vis spectroscopy (Figure 7a).

To understand the decoloration mechanism, the density functional theory (DFT, B3LYP/6-31G*) calculation of 1 and its leuco-hydroxide derivative (1-OH) was performed. As shown in Figure $7 \mathrm{~b}$, the three-blade propeller structure of OPC 1 with $D_{3}$ symmetry in its cationic form was obtained after the geometry optimization, which is composed of three aryl rings linked to a $s p^{2}$-hybridized central carbon atom, and the three bond-angles are all $119.9^{\circ}$. Due to the extensive delocalization of electrons on the arenes at its HOMO, it exhibits an energy gap of $2.91 \mathrm{eV}$ within its LUMO. It therefore indicates the cation 1 is a strong visible-light absorbent, which should absorb green light. ${ }^{3 \mathrm{C}}$ Whereas the configuration of neutralized form 1-OH is dramatically different, as the bond angles between three $\mathrm{C}$-C bonds connected to $s p^{3}$-hybridized central carbon atom are $114.7^{\circ}, 117.7^{\circ}$, and $107.8^{\circ}$, respectively. It reveals that the configuration of $\mathbf{1 - O H}$ is similar to a tetrahedral configuration. Unlike electrons delocalized over a wider range in the HOMO of the cationic form, the electrons of leuco-hydroxide 1$\mathrm{OH}$ are delocalized within a smaller range, resulting in a much larger energy gap (5.38 eV) between its HOMO and LUMO, revealing no absorption in the visible range at all. (Figure 7). This DFT calculation and comparision therefore explains the color change from purple cation 1 to its colorless neutralized form $1-0 H$. 
a)

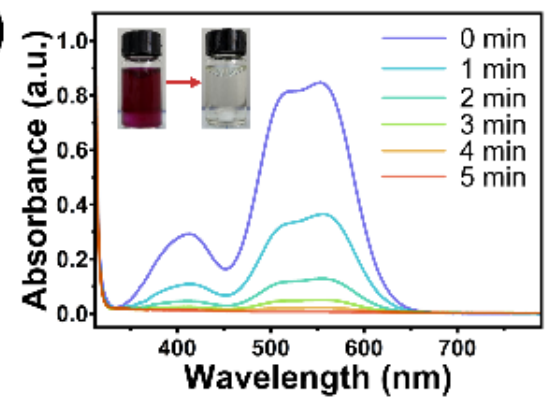

b)

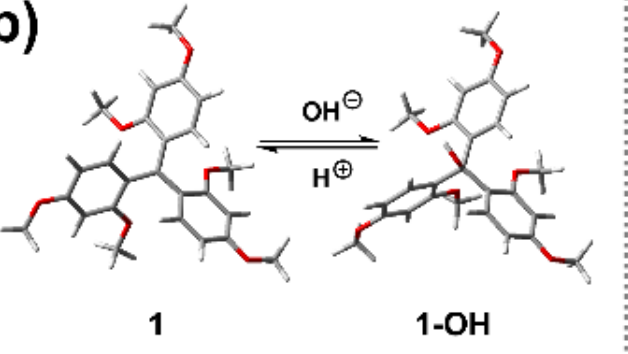

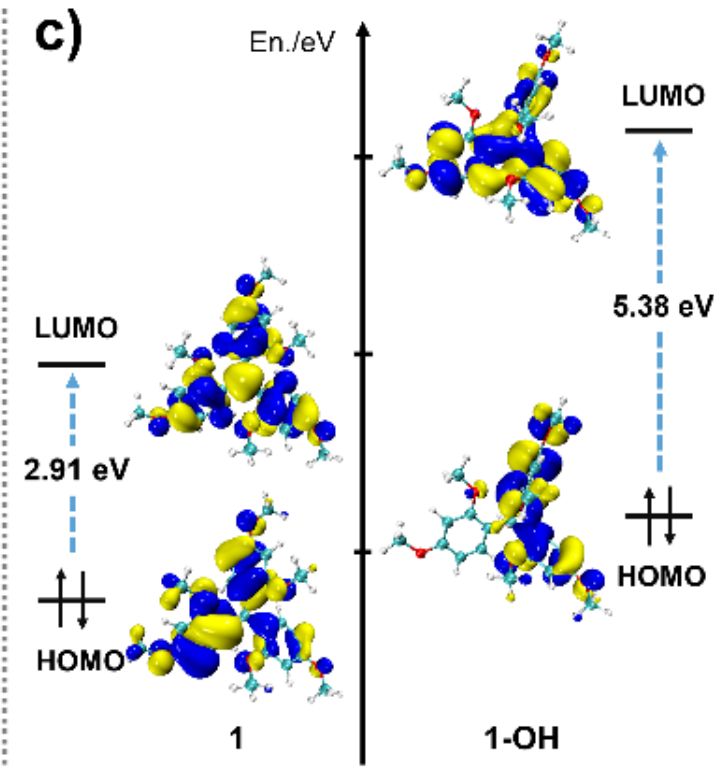

Figure 7. a) UV/vis absorption spectrum of the polymerization mixture after addition of triethylamine, inset showing the corresponding apparent color change of the mixture solution. b) Optimized chemical conformation of OPC 1 and 1$\mathrm{OH}$ and their transition mechanism (DFT, B3LYP/6-31G*). c) Frontier orbitals, energy levels and their potential gaps of the ground state of OPC 1 (left) and 1-OH (right) calculated by DFT (B3LYP/6-31G*).

To verify that the leuco-hydroxide derivative of OPC 1 indeed forfeits its inherent photocatalytic activity after its visible absorption vanishes, we attempted the photo-induced cationic polymerization by using $1-\mathrm{OH}$ as the OPC. No polymerization product was observed, indicating that the leuco-hydroxide derivative of OPC 1 is photocatalytic inactive, and the quenching of the residual OPC $\mathbf{1}$ is easily achieved by simple addition of a base, concomitant with its decoloration.

\section{Conclusion}

The photo-controlled living cationic polymerization of $p$-MOS using a metal-free organo-photocatalyst 1 and phosphate CTA 2 is showcased in the current manuscript. This living cationic polymerization not only successfully yielded poly( $p$-MOS) with predetermined molar mass and narrow $€$, but also exhibits excellent stable photo-control characteristics, which can inhibit chain growth during long dark periods (>36h). Most notably, we demonstrated, for the first time, that the erstwhile dark purple reaction mixture was easily decolored by simple addition of a base, yielding the resulting polymers as white powders. This is due to the deactivation of the OPC 1 cation, forming its $\mathbf{1 - O H}$ neutral form, which will no longer impose potential photolysis to the polymer product. The method presented here can also be extended to the living polymerization of other vinyl monomers or cyclic monomers by the modification of the photocatalysts and phosphates, which are in progress in our research group and will be reported in due course.

[1] a) J. Rzayev, J. Penelle, Angew. Chem. Int. Ed. 2004, 43, 1691-1694; Angew. Chem. 2004, 116, 17231726; b) A. J. Magenau, N. C. Strandwitz, A. Gennaro, K. Matyjaszewski, Science 2011, 332, 81-84; c) A. M. Doerr, J. M. Burroughs, S. R. Gitter, X. Yang, A. J. Boydston, B. K. Long, ACS Catal. 2020, 10, 14457-14515; d) F. A. Leibfarth, K. M. Mattson, B. P. Fors, H. A. Collins, C. Hawker, Angew. Chem. Int. Ed. 2013, 52, 199-210; Angew. Chem. 2013, 125, 210-222; e) Y. N. Zhou, J. J. Li, Y. Y. Wu, Z. H. Luo, Chem. Rev. 2020, 120, 2950-3048. 
[2] a) B. P. Fors, C. J. Hawker, Angew. Chem. Int. Ed. 2012, 51, 8850-8853; Angew. Chem. 2012, 124, 89808983; b) E. H. Discekici, A. Anastasaki, R. Kaminker, J. Willenbacher, N. P. Truong, C. Fleischmann, B. Oschmann, D. J. Lunn, J. Read de Alaniz, T. P. Davis, C. M. Bates, C. J. Hawker, J. Am. Chem. Soc. 2017, 139, 5939-5945; c) G. M. Miyake, J. C. Theriot, Macromolecules 2014, 47, 8255-8261; d) N. J. Treat, H. Sprafke, J. W. Kramer, P. G. Clark, B. E. Barton, J. Read de Alaniz, B. P. Fors, C. J. Hawker, J. Am. Chem. Soc. 2014, 136, 16096-16101; e) R. M. Pearson, C. H. Lim, B. G. McCarthy, C. B. Musgrave, G. M. Miyake, J. Am. Chem. Soc. 2016, 138, 11399-11407; f) J. C. Theriot, C. H. Lim, H. Yang, M. D. Ryan, C. B. Musgrave, G. M. Miyake, Science 2016, 352, 1082-1086; g) B. G. McCarthy, R. M. Pearson, C. H. Lim, S. M. Sartor, N. H. Damrauer, G. M. Miyake, J. Am. Chem. Soc. 2018, 140, 5088-5101; h) B. L. Buss, C. H. Lim, G. M. Miyake, Angew.Chem. Int. Ed. 2020, 59, 3209-3217; Angew. Chem. 2020, 132, 3235-3243; i) Q. Ma, J. Song, X. Zhang, Y. Jiang, L. Ji, S. Liao, Nat. Commun. 2021, 12, 1-8; j) V. K. Singh, C. Yu, S. Badgujar, Y. Kim, Y. Kwon, D. Kim, J. Lee, T. Akhter, G. Thangavel, L. S. Park, J. Lee, P. C. Nandajan, R. Wannemacher, B. Milián-Medina, L. Lüer, K. S. Kim, J. Gierschner, M. S. Kwon, Nat. Catal. 2018, 1, 794-804; k) N. Corrigan, C. Boyer, Trends in Chemistry. 2020, 2, 689-706; I) K. Parkatzidis, H. S. Wang, N. P. Truong, A. Anastasaki, Chem. 2020, 6, 1575-1588.

[3] a) J. Xu, K. Jung, A. Atme, S. Shanmugam, C. Boyer, J. Am. Chem. Soc. 2014, 136, 5508-5519; b) S. Shanmugam, J. Xu, C. Boyer, Angew. Chem. Int. Ed. 2016, 55, 1036-1040; Angew. Chem. 2016, 128, 1048-1052; c) C. Wu, H. Chen, N. Corrigan, K. Jung, X. Kan, Z. Li, W. Liu, J. Xu, C. Boyer, J. Am. Chem. Soc. 2019, 141, 8207-8220; d) N. Corrigan, S. Shanmugam, J. Xu, C. Boyer, Chem. Soc. Rev. 2016, 45, 6165-6212; e) S. Dadashi-Silab, S. Doran, Y. Yagci, Chem. Rev. 2016, 116, 10212-10275; f) M. Chen, S. Deng, Y. Gu, J. Lin, M. J. MacLeod, J. A. Johnson, J. Am. Chem. Soc. 2017, 139, 2257-2266; g) H. Gong, Y. Zhao, X. Shen, J. Lin, M. Chen, Angew. Chem. Int. Ed. 2018, 57, 333-337; Angew. Chem. 2018, 130, 339-343; h) H. Gong, Y. Gu, Y. Zhao, Q. Quan, S. Han, M. Chen, Angew. Chem. Int. Ed. 2020, 59, 919-927; Angew. Chem. 2020, 132, 929-937.

[4] a) K. A. Ogawa, A. E. Goetz, A. J. Boydston, J. Am. Chem. Soc. 2015, 137, 1400-1403; b) V. K. Kensy, R. L. Tritt, F. M. Haque, L. M. Murphy, D. B. Knorr, S. M. Grayson, A. J. Boydston, Angew. Chem. Int. Ed. 2020, 59, 9074-9079; Angew. Chem. 2020, 132, 9159-9164.

[5] X. Zhang, Q. Ma, Y. Jiang, S. Hu, J. Li, S. Liao, Polym. Chem. 2021, 12, 885-892.

[6] a) A. J. Perkowski, W. You, D. A. Nicewicz, J. Am. Chem. Soc. 2015, 137, 7580-7583; b) V. Kottisch, Q. Michaudel, B. P. Fors, J. Am. Chem. Soc. 2016, 138, 15535-15538; c) V. Kottisch, M. J. Supej, B. P. Fors, Angew. Chem. Int. Ed. 2018, 57, 8260-8264; Angew. Chem. 2018, 130, 8392-8396; d) X. Zhang, Y. Jiang, Q. Ma, S. Hu, S. Liao, J. Am. Chem. Soc. 2021, 143, 6357-6362.

[7] a) V. Kottisch, Q. Michaudel, B. P. Fors, J. Am. Chem. Soc. 2017, 139, 10665-10668; b) Q. Michaudel, V. Kottisch, B. P. Fors, Angew. Chem. Int. Ed. 2017, 56, 9670-9679; Angew. Chem. 2017, 129, 9798-9808.

[8] a) E. H. Discekici, A. Anastasaki, J. Read de Alaniz, C. J. Hawker, Macromolecules 2018, 51, 7421-7434; b) S. Shanmugam, J. Xu, C. Boyer, Macromol. Rapid Commun. 2017, 38, 1700143.

[9] a) S. Shanmugam, S. Xu, N. N. M. Adnan, C. Boyer, Macromolecules 2018, 51, 779-790; b) J. Jiang, G. Ye, Z. Wang, Y. Lu, J. Chen, K. Matyjaszewski, Angew. Chem. Int. Ed. 2018, 57, 12037-12218; Angew. Chem. 2018, 130, 12213-12218; c) X. Li, Y. C. Zhang, Y. Zhao, H. P. Zhao, B. Zhang, T. Cai, Macromolecules 2020, 53, 1550-1556.

[10] a) S. Oßwald, S. Breimaier, M. Linseis, R. F. Winter, Organometallics 2017, 36, 1993-2003; b) Z. Dong, H. H. Cramer, M. Schmidtmann, L. A. Paul, I. Siewert, T. Müller, J. Am. Chem. Soc. 2018, 140, 15419-15424. 
[11] a) Y. Zhang, E. Y. X. Chen, Macromolecules 2008, 41, 36-42; b) Y. Zhang, L. O. Gustafson, E. Y. X. Chen, J. Am. Chem. Soc. 2011, 133, 13674-13684.

[12] M. A. Miranda, H. Garcia, Chem. Rev. 1994, 94, 1063-1089.

[13] a). M. Uchiyama, K. Satoh, M. Kamigaito, Angew. Chem. Int. Ed. 2015, 54, 1924-1928; Angew. Chem. 2015, 127, 1944-1948; b) Q. Michaudel, T. Chauviré, V. Kottisch, M. J. Supej, K. J. Stawiasz, L. Shen, W. R. Zipfel, H. D. AbruñaOrcid, J. H. FreedOrcid, B. P. Fors, J. Am. Chem. Soc. 2017, 139, 15530-15538.

[14] a). A. Postma, T. P. Davis, G. Moad, M. S. O'Shea, Macromolecules 2005, 38, 5371-5374; b) Y. K. Chong, G. Moad, E. Rizzardo, S. H. Thang, Macromolecules 2007, 40, 4446-4455.

[15] M. Uchiyama, K. Satoh, M. Kamigaito, Polym. Chem. 2016, 7, 1387-1396.

[16] J. Lv, Q. Zhang, X. Zhong, S. Luo, J. Am. Chem. Soc. 2015, 137, 15576-15583.

[17] M. Nakamura, R. Dohno, T. Majima, J. Org. Chem. 1998, 63, 6258-6265.

[18] S. V. Kostjuk, A. V. Radchenko, F. Ganachaud, Macromolecules 2007, 40, 482-490.

[19] a) R. S. Givens, L. W. Kueper, Chem. Rev. 1993, 93, 55-66; b) M. Newcomb, J. H. Horner, P. O. Whitted, D. Crich, X. Huang, Q. Yao, H. Zipse, J. Am. Chem. Soc. 1999, 121, 10685-10694; c) C. Ma, W. M. Kwok, W. S. Chan, Y. Du, J. T. W. Kan, P. H. Toy, D. L. Phillips, J. Am. Chem. Soc. 2006, 128, 2558-2570. 